\title{
THE ROLE OF TERRITORIALITY IN CRIME PREVENTION: A FIELD EXPERIMENT
}

Richard Wortley

$\&$

Matthew McFarlane

Griffith University

Wortley, R. and McFarlane, M. (2011) The role of territoriality in crime prevention:

A field experiment. Security Journal, 24: 149-156. 


\begin{abstract}
A field experiment was conducted in a university library to assess the effect of symbolic territorial cues on preventing the theft of a photocopy card which was left on library desk. Territoriality was conceived as comprising two dimensions - ownership and guardianship. In a 2 X2 design, ownership was operationized by signing or not signing the card, and guardianship was operationized by leaving the card next to library books or on its own. Both territorial cues were successful in reducing theft levels. It was argued that the crime prevention role of territorial cues needs to be conceived of in terms that are broader than alerting potential offenders to increased levels of surveillance.
\end{abstract}




\section{INTRODUCTION}

Territoriality refers to the behaviors and psychological states associated with the perceived ownership of a physical space. In criminology, territoriality is most commonly encountered in situational crime prevention, introduced primarily through the work of architect Oscar Newman. Newman (1972) used territoriality as the basis for his concept of defensible space, which he defined as 'a surrogate term for the range of mechanisms - real and symbolic barriers, strongly defined areas of influence, and improved opportunities for surveillance- that combine to bring an environment under the control of its residents' (p. 3). According to Newman, potential offenders are sensitive to environmental cues that indicate an area is uncontrolled and open to criminal opportunities. Residents are encouraged to assume a greater sense of ownership over private and semi-public areas within their domain and to become more vigilant in recognising and deterring outsiders. Territoriality may be instilled in residents through the use of real and symbolic territorial markers - such as fences, warning signs, changes in paving surfaces, signs of personalisation - which also convey to potential intruders that the area is not public and is likely to be under surveillance.

The concept of territoriality has come to criminology from ethnology via psychology. There is an extensive body of animal research demonstrating territorial behavior in many species, including birds, mammals, reptiles and even insects (Edney, 1974; Hediger, 1950). Human territoriality subsequently became a popular topic in environmental psychology from the 1970s (Altman, 1975; Edney, 1974). However, despite the central place of territoriality in situational crime prevention, research specifically examining territoriality and criminal behaviour is sparse. Moreover, there are two main limitations with the research that does exist. First, the 
research methods that have been employed to date do not permit unambiguous conclusions to be drawn about the supposed crime prevention effects of territorial markers. Second, to the extent that the crime prevention effects can be demonstrated, little attention has been paid to investigating the psychological processes by which territorial markers deter prospective offenders.

\section{Methods of Studying Human Territoriality}

Human territoriality is difficult to research. Laboratory studies that permit randomised designs are generally impractical since territorial responses by definition require locations in which people feel some sense of ownership. Consequently, researchers have had to rely on alternative methods such as field experiments, naturalistic observations, and self-report studies.

Field experimentation involves the deliberate manipulation of territoriality cues in real world environments, and is the most powerful of the available designs. This method is common in psychological research. Typical is the study by Becker (1973), who investigated territorial invasion in a library by comparing occupancy at desks on which books had been left with occupancy at empty desks. Across five-hour periods, trained assistants recorded the pattern of occupation, density of library users, and the duration of each subject's stay at the table. Becker found that library users were less likely to occupy a marked table than an empty table. When invasion did occur occupants spent less time at a marked table than an empty table, and usually positioned themselves to be at the greatest distance possible from the marker. However, there appear to be no field experiments that have explicitly examined whether the deterrent effect of markers on invasion extends to preventing crime at the marked sites. 
Field observation involves behavioral comparisons in naturally occurring territories and has been the usual method in criminology of investigating territoriality. Newman's (1972) original insights on the effectiveness of defensible space in reducing crime were based on field observations. However, the research he cited often amounted to little more than illustrative case studies. For example, he noted instances of high-rise residential blocks that had real and symbolic barriers differentiating the building from the street and he pointed out that they were less vandalized than similar buildings that had no such barriers. Later research has been more systematic. Brown and Altman (1983), for example, used structured rating schedules to compare the characteristics of 306 burglarized and non-burglarized houses. They found that nonburglarized houses were more likely to have a range of territorial features, including symbolic indicators of ownership such as signs with the owner's name; actual barriers such as fences and locked gates; and signs of current occupation such as toys strewn on the front lawn. Nevertheless, despite the relative sophistication of such studies, the lack of control over variables and the difficulty in ruling out confounding influences leave the findings open to alternative explanations.

The third method of investigating territoriality and crime prevention has been self report by residents and offenders. For example, Brown and Bentley (1993) sought responses from incarcerated burglars to pictures of burglarized and non-burglarized houses. While respondents were not able to distinguish between the burglarized and non-burglarized houses, their ratings of the houses' vulnerability to burglary were consistently related to the presence or absence of territorial features. Houses that they rated as relatively low risk of burglary were also rated by them as more likely to be occupied, more difficult to enter, and better cared for by the owner. Again, however, studies such as this do not permit unambiguous conclusions to be drawn about the role 
of territorial cues, and have the additional problems of motivational distortion by respondents and a lack of ecological validity.

In summary, while psychological research using field experimentation has demonstrated the effectiveness of territorial markers in deterring intrusion, the crime prevention effects must be inferred. On the other hand, while criminological research using field observation and self report techniques has shown variations in crime rates at different sites, the attribution of cause to variations in territoriality must be inferred. Clearly what is required is field experimentation that systematically manipulates levels territoriality and includes outcome measures of criminal behavior.

\section{Explaining Deterrent Effects on Prospective Offenders}

Territoriality is defined in terms of the behavior of territorial possessors. Likewise, theories of territoriality focus on explanations of why species stake out territories. Original ethnological studies framed territoriality as an instinctual response, shaped by evolution and principally designed to help an organism secure food supplies and breeding sites (Ardrey, 1966; Lorenz, 1966). With the shift in focus from animals to humans, explanations broadened to include the role of learning and to acknowledge cultural variations in territorial behavior (Brown, 1987; Edney, 1974; Smith, 1981). While the behavior of potential intruders is sometimes the subject of research on human territoriality (as in the examples described in the previous section), theories of human territoriality give little consideration to why individuals respect (or violate) territorial boundaries. However, it is reasonable to assume that within a given species, there is a link between the psychological processes governing both the desire to possess territory and the reluctance to intrude on another's territory. Whether 
territoriality is instinctual, learned, or a combination of the two, territorial markers only work if both the possessor and potential intruder know the rules.

From a criminological perspective, understanding the behavior of the territorial invaders - likely offenders - is of major interest. However, in his appropriation of territoriality, Newman's (1972) had little say about offenders. His main concern was with instilling 'proprietary attitudes' (p. 9) in residents who then had the responsibility of guarding their newly-defined territory. Some territorial markers - for example, a high fence - obviously work because they present a physical barrier to intruders. But Newman stressed the power of symbolic markers - such as a row of plants instead of a fence - in fostering territoriality and deterring intrusion. In the defensible space model, the presumed power of symbolic territorial markers as crime prevention tools lies in the implied threat they convey to offenders of an increased risk of detection and apprehension through increased guardianship by residents. This assumption that the subjective perception of symbolic territorial markers by potential intruders involves rational assessments of risk has subsequently dominated criminological understandings of territoriality (Brown \& Altman, 1981; Brown \& Bentley, 1993; Brown, Perkins \& Brown, 2004; Brunson, Kuo \& Sullivan, 2001; Perkins, Wandersman, Rich \& Taylor, 1993; Taylor, Gottfredson \& Brower, 1984).

In the psychological literature, however, human territorial responses are conceived in terms that are broader than conscious motivations to defend one's possessions. Ownership is associated with a range of psychological benefits. 'Home turf' is a place to relax, to express one's identity, to feel a sense of belonging, and to be in control (Edney, 1974, 1975; Harris \& Brown, 1996). Conversely, individuals may experience psychological discomfort and reduced self-efficacy when they are on 
unfamiliar ground. In a field experiment, Taylor and Lanni (1981) found that in a group decision making exercise, the position advocated by the owner of the room in which the exercise took place was most strongly reflected in the final consensus. Similarly, in an analysis of home and way games in three sports (baseball, football and hockey) Schwartz and Barsky (1977) found the home team won 53-64\% of the time. It seems that violating another's territory has negative psychological effects on outsiders that are separate from the overt threat of confrontation with the owner.

In the criminological context, one possible psychological response to violating territory for the purpose of committing crime is an increased feeling of guilt. According to control theories of crime, self-condemnation is a powerful constraint on behavior. However, sometimes individuals make excuses for their illegal behavior and reduce inhibitory guilt responses by convincing themselves that their actions are justified (Sykes and Matza, 1957). Clarke and Homel (1997) argued that one way offenders avoid self-censure is by exploiting any ambiguity about the moral legitimacy of their actions. For example, they may 'souvenir' the dressing gown from their hotel room because there is no clear instruction not to do so. To counter this tendency, Clarke and Homel recommended 'rule setting' - making clear the expected standards of behavior - as a crime prevention strategy. Displaying territorial markers can be interpreted as a form of rule setting that reinforces to potential offenders that they are about to violate the property rights of another person. While territorial markers may well signal to potential offenders that there is an increased level of guardianship, the assertion of ownership may itself prompt honesty by evoking deterrent psychological effects. 
AIMS

The aim of the current research is to examine experimentally the role of symbolic territorial markers in preventing crime, and specifically, to tease out the relative effects on potential offenders of perceived ownership and perceived guardianship. It was hypothesized that both ownership cues and guardianship cues conveyed by symbolic territorial markers would deter potential offenders.

\section{METHOD}

A naturalistic experiment was set up in Griffith University library to examine the effects of territorial cues on the theft of photocopy cards. The cards were plastic and similar in size to a standard credit card. Students pay an initial \$10 deposit for the cards and then boost the credit available as required. Students do not need to show any identification when purchasing the card or additional credit, and there is no PIN required when using the photocopier. While there is a place for the students to sign their names on the card, many students do not bother to do so. Even if there is no credit left on the cards, students can return them anonymously to redeem the deposit. Thus, they are a transferable commodity, although the ones used in this study were in fact blank.

Territoriality was manipulated in a $2 \mathrm{X} 2$ design, incorporating two hypothesized dimensions of territoriality - ownership and guardianship. Ownership was operationalized by leaving either a signed ('M. Smith') or unsigned card on a library table (with the signature/no signature side showing). The signature made it clear that the card belonged to somebody, but did not imply an increased risk of detection. Guardianship was operationalized by placing the card either next to two library books, or on its own. It was reasoned that the library books would indicate to 
passer-bys that the owner of the card was nearby and likely to return at any time, while the absence of books would suggest that the card had simply been forgotten and the owner was likely to have left the room ${ }^{1}$.

The researcher occupied a table in one of the library's study rooms just after the library opened and set up one of the four experimental conditions. The researcher then left the study room and retired some distance to a vantage point from where the set-up could be observed without attracting suspicion. (The study rooms had large glass windows.) Each trial ran for two hours or until the card was removed, which ever came first. The order of the conditions was varied although a strictly randomized order could not be employed since each condition required a different number of trials. In order to minimize the risk of library users becoming aware of the study, only one trial was run per day and different locations around the library were used. The experiment ran over several months. Data collection ceased as soon as practicable after each condition had a received minimum of 500 minutes observation and times among conditions were roughly equivalent.

In order to assess the relative opportunities for theft in each condition, two population measures were taken. Density was measured by counting the number of people in the study room at the beginning of the set-up, then every 20 minutes thereafter, a calculating the average. Traffic was measured by counting the number of people who walked passed the set-up.

It was a condition of ethics approval that no-one taking a card was to be approached by the researcher. The study was conducted with the cooperation of library staff. After each trial, checks were made at the library desk to see if any cards were handed in as lost.

\footnotetext{
${ }^{1}$ In fact the presence of the books also indicates ownership. The two territorial dimensions might be more accurately described as 'ownership' and 'ownership plus guardianship'.
} 


\section{RESULTS}

Results are summarized in Table 1. There was trivial variation in total time devoted to each experimental condition. The greater number of trials for the no books/unsigned condition simply reflects the fact that a new trial was necessary each time a card was stolen. The shortest delay between the researcher leaving the room and the card being taken -2 minutes - occurred in this condition. There was no difference in average density levels among conditions $\left(\chi^{2}(2)=.24\right.$, ns). However, there was a significant difference in the traffic levels $\left(\chi^{2}(2)=8.15, p<.05\right)$, which is largely attributable to the relatively light traffic flow in the no books/signed condition.

Table 1 about here

It was not possible to analyze the number of cards stolen in a $2 \mathrm{X} 2$ Chi-square since expected frequencies in two cells fell below five. Therefore the main effects were examined separately. For the signed versus unsigned analysis, $\chi^{2}(1)=6.26$, $\mathrm{p}<.05$; and for the books versus no books analysis, $\chi^{2}(1)=13.37, \mathrm{p}<.01$. These results indicate that both kinds of territorial cues exerted a significant deterrent effect on potential card-takers. None of the removed cards was returned to the library desk by any of the participants.

\section{DISCUSSION}

The hypothesis that both ownership and guardianship cues would deter offenders was supported. Results show experimentally that symbolic territorial markers can be effective crime prevention tools. Further, results suggest that markers convey more to 
potential offenders that just an implied threat that an area is under surveillance; markers may also evoke the anticipation of psychological discomfort associated with violating another's property rights.

Three qualifications need to be raised with respect to the present findings. The first relates to the significant difference in traffic flow among the experimental conditions. It is unclear why there were fewer pedestrians in the no books/card signed condition, but this finding raises the possibility that the low level of theft in this condition is at least partly attributable to there being fewer people walking past the card. Examining thefts as a proportion of traffic goes some way to countering this criticism. In the no books/signed condition, on average a card was picked up for every 27.8 passer-bys, more than twice the number of passer-bys required for the no book/unsigned condition (13), although still fewer than required for the book/signed (101) and book/unsigned (112) conditions. Further, it is also noted that the other population measure - density - did not differ among conditions. There were no fewer potential card-takers in the room; they were just less mobile. However, it was not necessary to walk past the card in order to observe it.

The second qualification concerns the interpretation of the findings. It was theorized that library patrons would infer ownership in the signed card condition and would avoid taking the card because of anticipated feelings of guilt, whereas the book present condition would indicate to patrons that the card owner was nearby and they would avoid taking it through fear of detection. (To the extent that the presence of books also implies ownership, theft in this condition would also increase feelings of guilt). However, since we were not permitted to approach card-takers, it was not possible to conduct a manipulation check, nor to explore the motivations for taking or not talking the card. While we think that our suppositions are reasonable, it is possible 
that the library users placed interpretations on the experimental conditions that differed from those we have assumed, or that they avoided taking the card for reasons other than we have suggested. One strategy to address these issues is to replicate the study in simulated form, presenting subjects with pictures of the experimental conditions and obtaining self-report responses. The perennial problem with such simulations, of course, is the lack of ecological validity.

The third qualification concerns the relatively trivial nature of the crime examined and (presumably) the low level criminal dispositions possessed by participants in the study. It is unlikely that any of the card-takers went to the library with the intention of committing theft - picking up the card was impulsive and opportunistic. The extent to which the assertion of ownership without the added threat of an increased level of detection would deter premeditated crimes by determined offenders is debatable. Nevertheless, the practical significance of the findings for crime prevention should not be underestimated. A great deal of crime is opportunistic and is carried out by individuals who are not committed to criminal values. For many potential offenders, preventing crime requires a light touch. One of the criticisms of modern situational crime prevention is an over-reliance on obtrusive target hardening. Interestingly, while Newman (1972) based defensible space on the concept of guardianship, he nevertheless advocated subtlety in urban design, favoring symbolic barriers over real ones. The current findings suggest that worthwhile prevention can be achieved by strengthening the psychological controls individuals have over their behavior. 


\section{REFERENCES}

Altman, I. (1975). The environment and social behavior. Monterey, CA: Brooks/Cole

Ardrey, R. (1966). The territorial imperative. New York: Atheneum.

Becker, F. (1973). Study of spatial markers. Journal of Personality and Social Psychology, 26 (3), 439-445.

Brown, B.B. (1987). Territoriality. In D. Stokols \& I. Altman (eds.) Handbok of environmental psychology (vol 1). (pp. 505-531). New York: WileyInterscience.

Brown, B.B., \& Altman, I. (1983). Territoriality, street form, and residential burglary: An environmental analysis. Journal of Environmental Psychology, 3, 203-220. Brown, B.B., \& Bentley, D.L. (1993). Residential burglars judge risk: The role of territoriality. Journal of Environmental Psychology, 13, 51-61.

Brown, B., Perkins, D., \& Brown, G. (2003). Place attachment in a revitalizing neighbourhood: Individual and block levels of analysis. Journal of Environmental Psychology, 23 (3), 259-271.

Brunson, L., Kuo, F., \& Sullivan, W.C. (2001). Resident appropriation of defensible space in public housing: Implications for safety and community. Environment and Behavior, 33, 626-652.

Clarke, R.V., \& Homel, R. (1997). A revised classification of situational crime prevention techniques', in S. P. Lab, ed., Crime prevention at the crossroads, (21-35). Cincinnati, OH: Anderson.

Edney, J.J. (1974). Human territoriality. Psychological Bulletin, 81, 959-975.

Edney, J.J. (1975). Territoriality and control: A field experiment. Journal of Personality and Social Psychology, 31, 1108-1115. 
Harris, P.B., \& Brown, B.B. (1996). The home and identity display: Interpreting resident territoriality from home exteriors. Journal of Environmental Psychology, 16, 187-203.

Hediger, H. (1950). Wild animals in captivity. London: Butterworth

Lorenz, K. (1966). On aggression. New York: Harcourt Brace Jovanovich.

Newman, O. (1972). Defensible space. London: Architectural Press.

Perkins, D., Wandersman, A., Rich, R., \& Taylor, R. (1993). The physical environment of street crime: Defensible space, territoriality and incivilities. Journal of Environmental Psychology, 13, 29-49.

Schwartz, B., \& Barsky, S.P. (1977). The home advantage. Social Forces, 55, 641661.

Smith, H.W. (1981). Territorial spacing on a beach revisited: A cross-national exploration. Social Psychology Quarterly, 44, 132-137.

Sykes, G. and Matza, D. (1957). Techniques of neutralization: A theory of delinquency', American Journal of Sociology, 22: 664-670.

Taylor, R., Gottfredson, S., \& Brower, S. (1984). Block crime and fear: defensible space, local social ties, and territorial functioning. Journal of Research in Crime and Delinquency, 21 (4), 303-331.

Taylor, R.B., \& Lanni, J.C. (1981). Territorial dominance: The influence of the resident advantage in triadic decision making. Journal of Personality and Social Psychology, 41, 909-915. 
Table 1

\section{Books Present Books Absent}

\begin{tabular}{lccccc}
\cline { 2 - 3 } \multicolumn{1}{c}{ Measure } & Card Signed & Card Unsigned & & Card Signed & Card Unsigned \\
\hline Total time & $518 \mathrm{~min}$ & $533 \mathrm{~min}$ & & $527 \mathrm{~min}$ & $520 \mathrm{~min}$ \\
Number of trials & 6 & 5 & 7 & 20 \\
Shortest trial & $64 \mathrm{~min}$ & $63 \mathrm{~min}$ & $35 \mathrm{~min}$ & $2 \mathrm{~min}$ \\
Average Density & 23.6 & 21.1 & 20.7 & 14.8 \\
Total traffic & 202 & 224 & 139 & 234 \\
Cards taken & 2 & 2 & 5 & 18 \\
\hline
\end{tabular}

